\title{
Severe imported falciparum malaria among adults requiring intensive care: a retrospective study at the hospital for tropical diseases, London
}

\author{
Michael E Marks', Margaret Armstrong ${ }^{1}$, Muhiddin M Suvari², Steve Batson ${ }^{3}$, Christopher J M Whitty ${ }^{1}$,
} Peter L Chiodini ${ }^{2}$, Geoff Bellinghan ${ }^{3}$ and Justin F Doherty ${ }^{1 *}$

\begin{abstract}
Background: Malaria is the commonest imported infection in the UK. Malaria requiring ICU admission has a reported mortality of up to $25 \%$. The relationship between ethnicity, immunity, and risk of malaria is complex. The Malaria Score for Adults (MSA) and Coma Acidosis Malaria (CAM) score have recently been proposed to risk stratify patients with malaria.

Methods: Retrospective study of patients with WHO severe falciparum malaria admitted to ICU at the Hospital for Tropical Diseases, London, UK. The relationship between clinical variables and risk of death or a prolonged ICU stay were examined with logistic regression. The predictive value of the MSA and CAM score were calculated.

Results: 124 patients were included. Cerebral malaria and acute kidney injury occurred earlier (median day 1) than acute respiratory distress syndrome (median day 3). Six patients had community acquired bacterial co-infection. Eight patients were co-infected with HIV, five of whom were newly diagnosed. The positive predictive value of a CAM score $\geq 2$ or an MSA $\geq 5$ for death were $12 \%$ and $22 \%$ respectively. Five patients died. No variable was significantly associated with risk of death. There were no significant differences between individuals raised in endemic countries compared to non-endemic countries.

Conclusions: Mortality in patients managed in a specialist centre was low. Patients who died succumbed to complications associated with a prolonged stay on ICU rather than malaria per se. The clinical usefulness of the MSA and CAM score was limited. Co-infection with HIV was relatively common but compared to studies in children, bacteraemia was uncommon. The relationship between ethnicity and immunity to severe disease is complex.
\end{abstract}

\section{Background}

Approximately 1700 cases of imported malaria are seen each year in the United Kingdom, of which P. falciparum is both the most common and the most severe [1], and it remains the most significant imported parasitic infection in North America, Europe and Australasia [2-4]. While the number of deaths from imported malaria is low, it has the potential to cause significant morbidity. The case fatality rate for $P$. falciparum in the UK is less than $1 \%$ but in previous series the mortality rate for those patients requiring admission to an intensive care unit (ICU) as a result of malaria has varied from $7 \%$

\footnotetext{
* Correspondence: tom.doherty@uclh.nhs.uk

${ }^{1}$ The Hospital for Tropical Diseases, Mortimer Market Centre, Capper Street, London WC1E 6JB, UK

Full list of author information is available at the end of the article
}

to $25 \%$ [5-11]. Most data on severe malaria come from endemic countries. Severe imported malaria seen in non-endemic countries is a very different clinical entity, particularly in terms of the resources available to care for critically ill patients, median age at presentation (mainly children in Africa and young adults in Asian series) and the likely effect of partial immunity from previous infection on disease progression in endemic countries.

Identifying those at high risk of death is important for subsequent treatment decisions. The Glasgow Coma Score (GCS) is widely accepted as a tool for identifying patients most at risk of a poor outcome and cerebral malaria in a non-endemic setting is usually defined for practical purposes as a GCS $<11$. Recently two scoring systems - Malaria Score in Adults (MSA) [12] and the 
Coma Acidosis Malaria (CAM) Score [13] have been suggested as additional systems to identify those patients at higher risk of death. However, neither of these has previously been validated among patients with imported malaria.

Earlier reports of severe imported malaria have shown that cerebral malaria, adult respiratory distress syndrome (ARDS) and acute kidney injury (AKI) are the most common complications of malaria requiring admission to ICU [5-11]. The inclusion criteria for these studies have varied; some included patients with non-severe malaria admitted to ICU while others included all patients with malaria who met at least one of the World Health Organisation's (WHO) criteria for severe disease [14] regardless of whether or not they were admitted to ICU. Definitions of hyperparasitaemia also varied with $2 \%, 4 \%$ and $5 \%$ taken as cut-off values in different papers. Only two papers $[5,6]$ have included data on the rates of bacterial co-infection. None of these earlier studies have included patients treated with Artemisininbased therapy and in only one study [11] were exchange transfusions used. Data on any long term sequelae following severe imported malaria are also scarce.

The concept of immunity to malaria is widely accepted but poorly understood. In areas of high endemicity, children gradually acquire immunity to the disease as a result of repeated exposure to infection, such that by the age of approximately five years severe malaria is unlikely to occur. Should such a child then move away from an endemic area, this immunity is thought to be lost relatively quickly and, within a matter of months or years, the child would again be at risk of severe disease. Unfortunately, no laboratory marker of "immunity" to malaria has been identified. The length of time that an individual has lived in a malaria-endemic area is often used as a proxy for immunity. Conversely, people who were born and raised in parts of the world where malaria transmission does not occur are widely assumed to be "naïve" and therefore at higher risk of severe disease. We aimed to examine whether any previous exposure to malaria would have an appreciable effect on the manifestations of severe malaria by stratifying patients according to their perceived "immunity" [15]

The inter-relationship between malaria and HIV infection has been studied almost exclusively in endemic areas. Co-infection with malaria has been shown to have a detrimental effect on HIV viral load and to result in more frequent and more severe disease [16]. No data have been reported concerning the prevalence of HIV infection among patients with severe imported malaria.

This study therefore set out to examine the main questions around management of severe malaria in highresource non-endemic setting.

\section{Methods}

The Hospital for Tropical Diseases (HTD) in London is part of University College London Hospitals and serves as a tertiary referral centre for patients with imported tropical diseases, including malaria. The hospital sees approximately 75 patients with falciparum each year, of which about $10 \%$ are sufficiently unwell to require admission to ICU.

\section{Study population}

A retrospective study was conducted on all adult patients (>18 years) seen at HTD/UCLH between 1994 and 2010. During this period a total of 1616 patients with falciparum malaria were seen, of whom 165 were sufficiently unwell to require admission to intensive care. Patients were excluded if they did not meet at least one of the WHO criteria for severe disease (parasitaemia $>5 \%$, ARDS [bilateral pulmonary infiltrates and $\mathrm{PaO}_{2}$ : $\mathrm{FiO}_{2}$ ratio of $<26.7$, not attributed to left ventricular dysfunction in the opinion of the ICU clinician], impaired consciousness [seizures or GCS <11], multiple convulsions, shock [systolic BP $<80 \mathrm{mmHg}$ despite adequate filling], abnormal bleeding or coagulopathy [unexplained clinically significant bleeding or laboratory evidence of DIC), macroscopic haemoglobinuria, AKI [creatinine $>265$ $\mu \mathrm{mol} / \mathrm{L}$ ], jaundice [bilirubin $>50 \mu \mathrm{mol} / \mathrm{L}$ ], hyperlactaemia [arterial lactate $>5 \mathrm{mmol} / \mathrm{L}]$, acidosis $[\mathrm{pH}<7.35$ or serum bicarbonate $<15 \mathrm{mmol} / \mathrm{L}$ ], hypoglycaemia [blood glucose $<2.2 \mathrm{mmol} / \mathrm{L}$ ], severe anaemia [haemoglobin $<5 \mathrm{~g} / \mathrm{dL}]$ ) [12]. The diagnosis of malaria was made by microscopic examination of a blood film. Microscopy was used to quantify parasitaemia, the presence of schizonts and co-infections with other forms of Plasmodia (vivax, ovale, malariae). Most were referred to HTD from other hospitals where they had already received treatment for malaria and, if there was no evidence of asexual parasitaemia at the time of admission to HTD/UCLH ICU, they were excluded. Of 165 patients admitted to ICU, 32 had notes which could not be found, eight no longer had asexual parasites on their blood film and one did not fulfil any of the WHO criteria for severe disease, leaving a total study population of 124 .

\section{Data collection}

Demographic, travel, clinical, laboratory and modalities of treatment data were collected from clinical notes and laboratory databases using a standard case report form. Complications of malaria were defined according to WHO guidelines on severe malaria [14]. Blood cultures that were positive within 48 hours of admission were taken to represent community-acquired infection; positive cultures after this time were defined as nosocomial. For the purposes of analyses, patients were classified as 
'malaria-naïve' if they had been born and raised outside a malaria-endemic area. Patients who were born in an endemic area but who had moved away a minimum of two years earlier were classified as having "little" immunity to malaria. Patients who were born and still resident in an endemic area at the time of admission were assumed to have "some" immunity to malaria.

\section{Management}

All patients were managed according to UK guidelines [17]. Until 2007, these recommended a loading dose of quinine $(20 \mathrm{mg} / \mathrm{kg})$ given intravenously over 4 hours, followed by $10 \mathrm{mg} / \mathrm{kg}$ until such time as a blood film was negative for asexual parasites. Exchange transfusion was considered for patients with a parasitaemia greater than $20 \%$ or those who had a parasitaemia greater than $10 \%$ with evidence of end-organ dysfunction. After 2007, intra-venous artesunate replaced quinine as first-line treatment for patients with a parasitaemia greater than $10 \%$ at HTD, depending on drug availability. All patients received a second anti-malarial agent, most commonly sulfadoxine/pyrimethamine. Decisions concerning organ support and adjunctive therapy were made exclusively by ICU staff.

\section{Statistical analyses}

Continuous variables were described with mean and standard deviation (SD) or with median and interquartile range (IQR) as appropriate. Categorical data were described with numbers and percent. "Severe ICU malaria" was defined as death or an ICU stay greater than seven days. The patients' MSA and CAM scores on admission to hospital were calculated as previously described $[12,13]$. The relationship between the MSA and CAM scores and risk of death and severe ICU malaria were compared using chi-square. Logistic regression was used to examine variables, including in the model the presence or absence of complications, age, gender and immune status, to determine factors associated with either death or severe ICU malaria. All analyses were carried out using Stata 10 (Statacorp).

\section{Ethics approval}

The study was reviewed and approved by the Audit and Research Committee at HTD who granted ethical approval for the study and stated that individual patient consent was not required as this was a retrospective case note review.

\section{Results}

\section{Patient characteristics}

Demographic data are shown in Table 1. Most $(n=103$, 83\%). were transferred to UCLH from another centre. The median time from initial admission to transfer to UCLH was 16 hours (IQR $8-30$ hours). The largest group were Caucasian $(61,49 \%)$, while 41 (33\%) were African. Very few took antimalarial chemoprophylaxis. Only one patient claimed to be fully adherent with an appropriate regimen. Nearly all $(116,94 \%)$ acquired their infection in sub-Saharan Africa. Seven had a clear history of having received treatment for malaria in the past. Three were already known to have HIV infection.

Table 1 Demographics

\begin{tabular}{|c|c|c|}
\hline \multicolumn{2}{|c|}{ Male } & $78(63 \%)$ \\
\hline \multicolumn{2}{|c|}{ Age - years - median (IQR) } & $46(35-55)$ \\
\hline \multirow[t]{4}{*}{ Ethnicity } & Caucasian & $61(49 \%)$ \\
\hline & African & $41(33 \%)$ \\
\hline & Other & $18(15 \%)$ \\
\hline & Unknown & $4(3 \%)$ \\
\hline \multirow[t]{4}{*}{ Previous malaria exposure } & Raised outside endemic area & $68(55 \%)$ \\
\hline & Born in endemic area + left $>2$ years ago & $46(37 \%)$ \\
\hline & Born and still resident in endemic area & $7(6 \%)$ \\
\hline & Unknown & $3(2 \%)$ \\
\hline \multirow[t]{5}{*}{ Travel to sub-Saharan Africa Chemoprophylaxis } & $116(94 \%)$ & \\
\hline & None & $87(70 \%)$ \\
\hline & Inadequate & $25(20 \%)$ \\
\hline & Adequate & $1(1 \%)$ \\
\hline & Unknown & $11(9 \%)$ \\
\hline \multicolumn{2}{|c|}{ Reported previous malaria } & $7(6 \%)$ \\
\hline \multicolumn{2}{|c|}{ Known HIV } & $3(3 \%)$ \\
\hline \multicolumn{2}{|c|}{ Time from returning to UK and admission - median days (IQR) } & $9.5(3-14)$ \\
\hline \multicolumn{2}{|c|}{ Time from symptom onset to seeking healthcare - median days (IQR) } & $4(3-6)$ \\
\hline
\end{tabular}


Median time since returning to the UK was 10 days (IQR 3-14). Median time from symptom onset to presentation was four days (IQR 3-6).

Sixty-eight (55\%) were classified as malaria-naïve. Forty-six (37\%) were assumed to have "little" immunity to malaria as they had grown up in an endemic area. Seven were both born and usually resident in a malariaendemic area at the time of admission and were assumed to have at least "some" degree of immunity.

\section{Malaria diagnosis}

Median parasitaemia at admission, either to UCLH or the referring hospital, was 6.1\% (IQR 2.6 - 18\%). Ninety eight (79\%) and 73 (59\%) had a parasitaemia greater than $2 \%$ and $5 \%$ respectively. One hundred and eight (87\%) and $82(66 \%)$ patients had at least one parasite count greater than $2 \%$ and $5 \%$ respectively during admission. Twenty-two (18\%) had schizonts at admission, and a further 53 (43\%) had schizonts at some time during admission. Four had mixed infections, two with $P$. malariae, and one each with $P$. vivax and $P$. ovale.

\section{Management}

One hundred and twenty three (99\%) received intravenous quinine as their initial treatment, 93 (76\%) of whom received a loading dose. Twenty were subsequently switched to an artemisinin derivative, 18 of whom received artesunate. One was treated with an artemisinin derivative from the start.

Thirty-three (27\%), with a median parasitaemia of $25 \%$, had an exchange transfusion performed. Forty six (37\%) required ventilation at some time. Similarly 43 (35\%) required renal replacement therapy and 43 (35\%) required inotropic support. Median length of stay in ICU was 10 days (IQR 7-19) but several had a prolonged stay, the longest being 90 days.

\section{Complications of malaria}

Patients met a median of three (IQR 2-5) WHO criteria for severe disease (Table 2). $80 \%$ of those with cerebral malaria and $75 \%$ of those with AKI developed these complications within 48 hours and tended to recover relatively quickly. In contrast, only two patients had ARDS at admission, while a further 22 developed ARDS later on, with a median time from admission to diagnosis of ARDS of three days (Figure 1). Patients with cerebral malaria and / or AKI had a higher parasitaemia at the time these complications became apparent compared to those patients who developed ARDS (Figure 2).

More than half $(68,55 \%)$ were acidotic at some stage. Hypoglycaemia (defined as blood glucose $<2.2 \mathrm{mmol} / \mathrm{L}$ ) was not seen at admission but five patients, all treated with intravenous quinine, developed this at some point. Shock occurred in 34 (27\%). Significant bleeding or coagulopathy was less common, occurring in 13 (11\%) patients most of whom had laboratory evidence of DIC. One patient, who ultimately made a complete recovery, sustained spontaneous rupture of their spleen. Another developed purpura fulminans, which necessitated bilateral below-knee amputations.

\section{Co-infections}

Six had a community-acquired co-infection; three had clinical and/or radiographic evidence of pneumonia while one had a coincidental buttock abscess. Two patients had a positive blood culture at admission, one Staphylococcus aureus and another Klebsiella pneumoniae. In one other, Mycobacterium tuberculosis was found in a sputum sample.

Twenty (16\%) developed nosocomial infection during their stay most commonly caused by Staphylococcus aureus ( $\mathrm{n}=7)$, Haemophilus influenzae $(\mathrm{n}=5)$ and Pseudomonas $(\mathrm{n}=2)$. Sixteen developed pneumonia, two had proven fungal infection, one bacteraemia with Staphylococcus aureus and one an episode of Clostridium difficile

Table 2 Manifestations of severe disease

\begin{tabular}{cccc}
\hline & & Present at admission & During admission \\
\hline Hyperparasitaemia & $>2 \%$ & $98(79 \%)$ & $108(87 \%)$ \\
\cline { 2 - 4 } & $>5 \%$ & $73(59 \%)$ & $82(66 \%)$ \\
\hline Acidosis pH $<7.35$ & & $37(30 \%)$ & $68(55 \%)$ \\
\hline AKl: creatinine $>265 \mu \mathrm{mol} / \mathrm{L}$ & $28(23 \%)$ & $55(44 \%)$ \\
\hline GCS $<11$ & $19(15 \%)$ & $44(35 \%)$ \\
\hline Shock: systolic BP $<80 \mathrm{mmHg}$ & $15(12 \%)$ & $34(27 \%)$ \\
\hline Coagulopathy & $7(6 \%)$ & $13(11 \%)$ \\
\hline Seizures & $4(3 \%)$ & $9(7 \%)$ \\
\hline ARDS & $2(2 \%)$ & $24(19 \%)$ \\
\hline Hypoglycaemia $<2.2 \mathrm{mmol} / \mathrm{L}$ & $0(0 \%)$ & $5(4 \%)$ \\
\hline
\end{tabular}




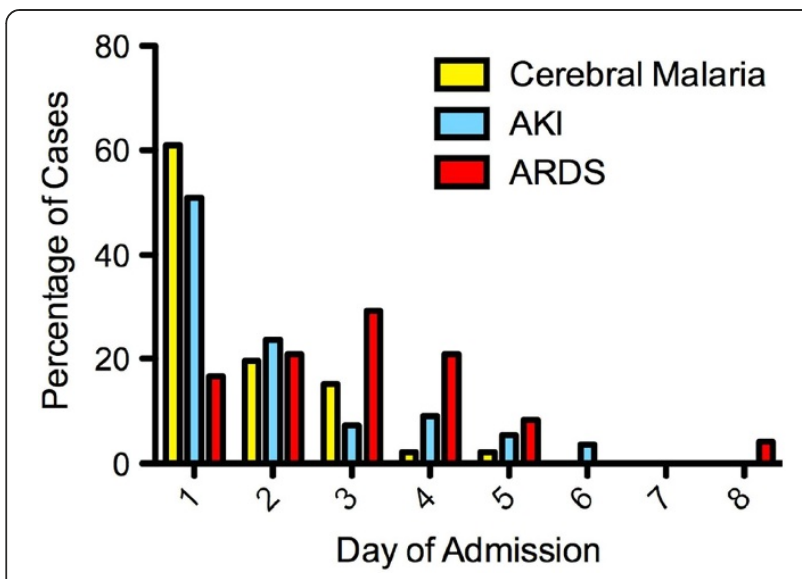

Figure 1 Timing of major manifestations of severe malaria. Cerebral malaria and acute renal failure most commonly occurred within 48 hours of presentation. ARDS was an uncommon manifestation of severe infection at presentation; most cases occurred from the third day of admission on.

colitis. Three patients, all African, were previously known to have HIV. Of 22 patients who were tested for HIV during admission, a further five were found to be positive, four of whom were African.

\section{Outcomes}

One hundred and nineteen (96\%) survived and all but one, the patient who developed purpura fulminans, ultimately made a complete recovery. Of the five patients who died, four were Caucasian; one was an African woman who had grown up in sub-Saharan Africa but left two years previously (Table 3 ). Their median parasitaemia was $18 \%$ (range $3.2-26 \%$ ) and four had schizonts. All five were acidotic, all had AKI, three had either

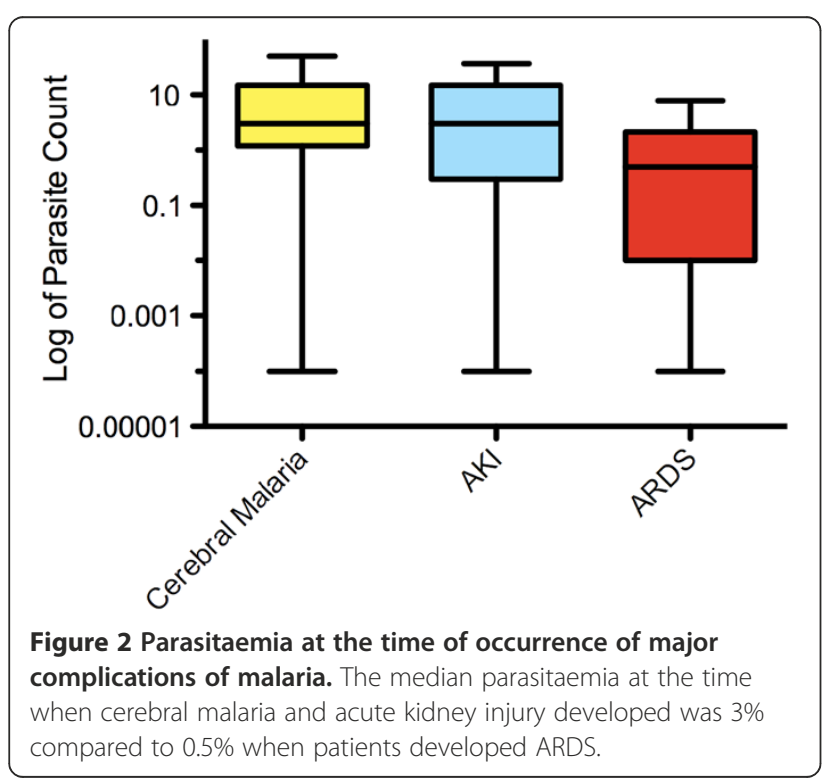

seizures or a GCS $<11$ and two developed ARDS. Four required mechanical ventilation, four required renal replacement therapy, three had an exchange transfusion and in four of the five cases the malaria film was negative at the time of death. In only one could the cause of death be directly attributed to malaria, a patient who died of multi-organ failure on day three when their parasitaemia was still more than $2 \%$. One patient died on day four as a result of cardiac arrhythmias which may have been precipitated by high-dose inotropes. The other three patients all died as a result of complications associated with prolonged ICU stay (disseminated fungal infection; multi-organ failure; staphylococcal pneumonia).

Twelve had persisting renal impairment at the time of discharge from ICU, but all of these ultimately recovered. After discharge from hospital, three needed readmission, one patient developed an acute confusional state which was diagnosed as a post malaria neurological syndrome and the patient made a complete recovery while two had a relapse of $P$. falciparum which responded to a further course of treatment.

There was no demonstrable association between the amount of "immunity" to malaria (naïve, "little") and the risk of severe ICU malaria (69\% vs $63 \%, \mathrm{p}=0.54$ ), cerebral malaria ( $67 \%$ vs $65 \%, \mathrm{p}=0.83)$, ARDS (78\% vs $85 \%$, $\mathrm{p}=0.34)$ or AKI $(61 \%$ vs $46 \%, \mathrm{p}=0.10)$. In logistic regression adjusting for the potential confounding factors outlined in the methods, no clinical factor was significantly associated with either death or severe ICU malaria.

A CAM score and an MSA score could be calculated at admission for 94 (76\%) and 124 (100\%) respectively. The positive predictive value of a CAM score $<2$ and an MSA score $<5$ for survival were $100 \%$ and $97 \%$ respectively. The positive predictive value of a CAM score $\geq 2$ or an MSA $\geq 5$ for death were $12 \%$ and $22 \%$ respectively. A CAM score $\geq 2$ was significantly associated with an increased risk of death $(12 \%$ vs $0 \%, \mathrm{p}=0.02)$ and of severe ICU malaria ( $50 \%$ vs $21 \%, \mathrm{p}=0.003$ ). An MSA score $\geq 5$ was associated with an increased risk of death (22\% vs $3 \%, \mathrm{p}=0.04$ ) but was not associated with a statistically significant increased risk of severe ICU malaria (44\% vs $33 \%, \mathrm{p}=0.49)$.

\section{Discussion}

This report shows that patients with severe malaria requiring admission to ICU who are managed at a specialist centre have a good outcome, with a mortality rate of only $4 \%$. Consistent with previous reports, acute kidney injury, ARDS, and cerebral malaria were the most common complications. This report demonstrates that ARDS occurs later and at lower parasitaemia and emphasises the need for vigilance even after patients appear to be responding to treatment. The data reinforce the 
Table 3 Clinical characteristics of patients who died

\begin{tabular}{|c|c|c|c|c|c|}
\hline $\begin{array}{l}\text { Patient } \\
\text { No. }\end{array}$ & Demographics & Travel data & $\begin{array}{l}\text { Manifestations of severe } \\
\text { malaria }\end{array}$ & $\begin{array}{l}\text { ICU } \\
\text { support }\end{array}$ & Death \\
\hline \multirow[t]{5}{*}{1} & $\begin{array}{l}31 \text { year old } \\
\text { female }\end{array}$ & Travelled to Zambia & Hyperparasitaemia & Exchange & Died Day 3 \\
\hline & Black African & No Chemoprophylaxis & Seizures & transfusion & Parasite Count 2.1\% \\
\hline & $\begin{array}{l}\text { Raised in } \\
\text { Endemic }\end{array}$ & & ARDS & Ventilated & \\
\hline & Region & & AKI & RRT & \\
\hline & & & Acidosis & Inotropes & \\
\hline \multirow[t]{5}{*}{2} & 25 year old male & Travelled to Uganda and & Hyperparasitaemia & Exchange & Died Day 19 \\
\hline & White & Kenya & AKI & transfusion & Disseminated fungal infection \\
\hline & Not-Raised in & No Chemoprophylaxis & Acidosis & RRT & \\
\hline & Endemic Region & Treatment for malaria & & & \\
\hline & & $\begin{array}{l}\text { started abroad: Chloroquine then } \\
\text { Quinine }\end{array}$ & & & \\
\hline \multirow[t]{6}{*}{3} & 83 year old male & Travelled to Kenya & AKI & Exchange & Died Day 9 \\
\hline & White & No Chemoprophylaxis & ARDS & transfusion & $\begin{array}{l}\text { Multi-organ failure, shock with } \\
\text { limb }\end{array}$ \\
\hline & Not-Raised in & & $\mathrm{GCS}<11$ & Ventilated & \\
\hline & Endemic Region & & Acidosis & RRT & \\
\hline & & & Shock & Inotropes & \\
\hline & & & Coagulopathy & & \\
\hline \multirow[t]{4}{*}{4} & 41 year old male & Travelled to Gambia & Hyperparasitaemia & Ventilated & Died Day 4 \\
\hline & White & No Chemoprophylaxis & Acidodsis & Inotropes & VT followed by Cardiac Arrest \\
\hline & Not-Raised in & & AKI & & \\
\hline & Endemic Region & & $\mathrm{GCS}<11$ & & \\
\hline \multirow[t]{4}{*}{5} & 47 year old male & Living in Liberia for 2 Years & Hyperparasitaemia & Ventilated & Died Day 11 \\
\hline & White & No Chemoprophylaxis & AKI & RRT & Staphylococcal pneumonia \\
\hline & Not-Raised in & & Acidosis & Inotropes & \\
\hline & Endemic Region & & & & \\
\hline
\end{tabular}

idea that there is a complex inter-relationship between ethnicity, "immunity" and the response to malaria. There were no significant differences between those individuals who had grown up in an endemic region and those patients who were malaria-naive. Co-infection with HIV was common, especially in patients who were African in origin. Finally, this report adds to the limited number of series reporting the efficacy and safety of parenteral artemisinins in severe malaria in a non-endemic setting [18-20]. The introduction of these agents has been associated with a dramatic reduction in the need for exchange transfusion.

In this series, the case-fatality rate was $4 \%$. In contrast, a paper from Kilifi [21] showed that African children who had evidence of cerebral malaria, acidosis and severe anaemia had a $35 \%$ risk of death. In the SEAQUAMAT trial [22], among young Asian adults, the group treated with quinine had a mortality of $22 \%$. In Africa, most deaths occur within the first 24 hours and children who survive beyond three days are much less likely to die. In this series, only one death occurred at a time when there was evidence of active malarial infection and the other four resulted from complications associated with intensive care, such as cardiac arrhythmia or nosocomial infection. Previous studies have reported a mortality rate between seven and 25\% [5-11]. Recent data from the Malaria Reference Laboratory have shown a marked geographical variation in mortality from imported malaria from different parts of the UK [23]. It is possible that the lower mortality in various specialist centres may be a reflection of wider experience in the management of severe malaria.

Most patients were young, Caucasian travellers to Africa but the second largest group were Africans visiting friends and relatives. For both groups, adherence to chemoprophylaxis was poor. The UK Health Protection Agency have previously reported an increased risk of acquiring malaria in individuals travelling to visit friends and relatives [1]. Between 1994 and 2010, HTD treated 1451 patients for falciparum malaria who did not require 
admission to ICU. Among all these patients, Africans were significantly less likely than Caucasians to require ICU admission (OR: 0.26 95\% CI: 0.18-0.38) which is in keeping with earlier reports [24]. However, among those who did require intensive care, Africans were no less sick. There were no differences in the number of WHO markers of severity between Africans and other ethnicities, suggesting that Africans admitted to ICU had no appreciable immunity to the disease. These findings highlight the inherent problems in using ethnicity as a proxy for "immunity" to malaria.

Cerebral involvement and/or AKI tended to be present on admission or develop within the first 48 hours. ARDS tended to develop later, often when there was little or no evidence of persisting malaria. Those caring for patients with severe malaria need to be aware that an initial response to treatment, manifest by a reduction in parasitaemia, does not necessarily mean a successful outcome.

Before the introduction of artesunate, this hospital recommended a six-unit exchange transfusion for patients with a parasitaemia greater than $20 \%$ or those with a parasitaemia greater than $10 \%$ but with evidence of end-organ dysfunction. In total, 33 (26\%) patients had an exchange transfusion, including three of the five who died. Since switching to parenteral artemisinins, we have seen evidence of a rapid and dramatic decline in parasitaemia compared to the response to treatment with quinine. As a result, we have not performed an exchange transfusion since 2008 and, in agreement with other UK specialist centres such as the Liverpool School of Tropical Medicine (D Lalloo, personal communication), we no longer recommend this as a modality of treatment.

Children presenting to African hospitals with malaria often have positive cultures for gram-negative organisms, particularly non-typhoidal salmonellae. The rate of blood culture positivity can be as high as $12 \%[25,26]$. Co-existing bacteraemia has been inconsistently reported in other series of imported malaria, with rates between 2.5 and $5 \%[5,6]$; in this series, only two (1.6\%) patients had positive blood cultures at admission, neither of which were salmonellae.

The extent of the interaction between HIV and falciparum malaria remains open to debate, but in subSaharan Africa, HIV positive pregnant women in particular appear to be at an increased risk of developing severe disease [27]. In this series, three patients were already known to be living with HIV/AIDS before they developed malaria; a further five were found to have HIV during admission, four of whom were African. A minimum of $17 \%$ of Africans therefore were positive for HIV, which will be an underestimate as not all were tested. These findings and the shared epidemiological risk factors for both diseases suggest that all patients presenting with severe malaria should be tested for HIV.
This study shows that both a CAM score $<2$ and an MSA $<5$ identified patients who would survive. However, these scores had limited ability to predict mortality and it remains unclear what role, if any, they may play in clinical practice in areas of the world where malaria is not endemic. No clinical factor was associated with a poor outcome but given the low case fatality rate, the study was under-powered to detect such a difference.

The main limitation of this study was its retrospective nature; as a result some data were missing or incomplete. Despite this, data capture was high, in particular data relating to ICU care, which were recorded systematically. Although the possibility of referral bias can not be excluded it is likely that our data are applicable to all patients with imported malaria requiring admission to ICU.

\section{Conclusions}

This paper suggests that most adult patients with severe malaria who are managed in a specialist centre survive. Cerebral malaria and AKI tend to occur early in the disease, while ARDS develops later. Patients who die tend to do so because of complications associated with intensive care rather than malaria per se. Africans who have left an endemic area seem to be at the same risk of severe disease as malaria-naive individuals. The increasing use of artesunate has been associated with a reduced need for exchange transfusion, even in patients with very high parasitaemia. In contrast to children, bacterial coinfections were uncommon. No single factor consistently identified individuals at risk of death. Both the MSA and CAM scores accurately predicted survival in low-risk patients but had limited power to identify those at high risk of death. All patients with malaria should be screened for HIV.

\section{Competing interests}

The authors declare that they have no competing interests.

\section{Authors' contributions}

MM extracted the data, carried out the analysis and wrote the initial draft of the paper. MA designed the research database and helped extract the data. MMS and PLC advised on the collection and analysis of data on the diagnosis of malaria and helped draft these sections of the manuscript. SB and GB generated the initial ICU dataset and advised on the collection and interpretation of all data relating to intensive care stay of patients. CJMW designed and carried out the statistical analysis. JD conceived of the study and helped draft the manuscript. All authors read and approved the final manuscript.

\section{Acknowledgements}

All the staff of the Intensive Care Unit at UCLH and colleagues at the Hospital for Tropical Diseases who helped look after these patients: Robin Bailey, Ron Behrens, Mike Brown, Peter Godfrey-Faussett, Philip Gothard, Alison Grant, Diana Lockwood, David Mabey, David Moore, Stephen Wright. The Department of Microbiology at UCLH for the microbiology data. Richard Jennings and Behzad Nadjm for their help with earlier versions of the database. 


\section{Funding}

This study was supported by the Special Trustees of the Hospital for Tropical Diseases. Margaret Armstrong is supported by The Special Trustees of the Hospital for Tropical Diseases. All authors are supported by the University College London Hospitals Comprehensive Biomedical Research Centre Infection Theme. The funding agencies had no role in study design, data collection and analysis, decision to publish, or preparation of the manuscript.

\section{Author details}

'The Hospital for Tropical Diseases, Mortimer Market Centre, Capper Street, London WC1E 6JB, UK. ${ }^{2}$ Department of Clinical Parasitology, Hospital for Tropical Diseases, Mortimer Market Centre, Capper Street, London WC1E 6JB, UK. ${ }^{3}$ Intensive Care Unit, University College London Hospitals, Euston Road, London NW1, UK.

Received: 18 October 2012 Accepted: 27 February 2013

Published: 5 March 2013

\section{References}

1. Smith AD, Bradley DJ, Smith V, Blaze M, Behrens RH, Chiodini PL, et al: Imported malaria and high risk groups: observational study using UK surveillance data 1987-2006. BMJ 2008, 337:a120.

2. Odolini S, Parola P, Gkrania-Klotsas E, Caumes E, Schlagenhauf P, LópezVélez $R$, et al: Travel-related imported infections in Europe, EuroTravNet 2009. Clin Microbiol Infect 2012, 18(5):468-474.

3. Seringe E, Thellier M, Fontanet A, Legros F, Bouchaud O, Ancelle T, et al: Severe imported plasmodium falciparum malaria, France, 1996-2003. Emerg Infect Dis 2011, 17(5):807-813.

4. Mali S, Kachur SP, Arguin PM, et al: Malaria surveillance-united states, 2009. MMWR Surveill Summ 2012, 61(2):1.

5. Bruneel F, Tubach F, Corne P, Megarbane B, Mira J-P, Peytel E, et al: Severe imported falciparum malaria: a cohort study in $\mathbf{4 0 0}$ critically III adults. PLoS One 2010, 5(10):e13236.

6. Bruneel F, Hocqueloux L, Alberti C, Wolff M, Chevret S, Bédos J-P, et al: The clinical spectrum of severe imported falciparum malaria in the intensive care unit: report of 188 cases in adults. Am J Respir Crit Care Med 2003, 167(5):684-689.

7. Santos LC, Abreu CF, Xerinda SM, Tavares M, Lucas R, Sarmento AC: Severe imported malaria in an intensive care unit: a review of 59 cases. Malar J 2012, 11(1):96.

8. Badiaga S, Brouqui P, Carpentier JP, Hovette P, Duigou F, Manelli JC, et al: Severe imported malaria: clinical presentation at the time of hospital admission and outcome in 42 cases diagnosed from 1996 to 2002. J Emerg Med 2005, 29(4):375-382.

9. González A, Nicolás JM, Muñoz J, Castro P, Mas J, Valls ME, et al: Severe imported malaria in adults: retrospective study of 20 cases. Am J Trop Med Hyg 2009, 81(4):595-599.

10. Schwake L, Streit JP, Edler L, Encke J, Stremmel W, Junghanss T: Early treatment of imported falciparum malaria in the intermediate and intensive care unit setting: an 8-year single-center retrospective study. Crit Care 2008, 12(1):R22.

11. Thierfelder C, Schill C, Hatz C, Nüesch R: Trends in imported malaria to Basel, Switzerland. J Travel Med 2008, 15(6):432-436.

12. Mishra SK, Panigrahi P, Mishra R, Mohanty S: Prediction of outcome in adults with severe falciparum malaria: a new scoring system. Malar J 2007, 6(1):24.

13. Hanson J, Lee SJ, Mohanty S, Faiz MA, Anstey NM, Charunwatthana P, et al: A simple score to predict the outcome of severe malaria in adults. Clin Infect Dis 2010, 50(5):679-685.

14. World Health Organization: Severe falciparum malaria. Trans $R$ Soc Trop Med Hyg 2000, 94(Supplement 1):1-90.

15. Jennings RM, De Souza JB, Todd JE, Armstrong M, Flanagan KL, Riley EM, et al: Imported plasmodium falciparum malaria: Are patients originating from disease-endemic areas less likely to develop severe disease? a prospective observational study. AmJTrop Med Hyg 2006, 75(6):1195-1199.

16. Reithinger R, Kamya MR, Whitty CJ, Dorsey G, Vermund SH: Interaction of malaria and HIV in Africa. BMJ 2009, 338(1):b2141.

17. Lalloo DG, Shingadia D, Pasvol G, Chiodini PL, Whitty CJ, Beeching NJ, et al: UK malaria treatment guidelines. J Infect 2007, 54(2):111-121.
18. Zoller T, Junghanss T, Kapaun A, Gjorup I, Richter J, Hugo-Persson M, et al: Intravenous artesunate for severe malaria in travelers, Europe. Emerg Infect Dis 2011, 17(5):771-777.

19. Kreeftmeijer-Vegter AR, van Genderen PJ, Visser LG, Bierman WF, Clerinx J, van Veldhuizen CK, et al: Treatment outcome of intravenous artesunate in patients with severe malaria in the Netherlands and Belgium. Malar $J$ 2012, 11(1):102.

20. Mørch K, Strand $\varnothing$, Dunlop O, Berg Å, Langeland N, Leiva RAM, et al: Severe malaria and artesunate treatment, Norway. Emerg Infect Dis 2008, 14(11):1816-1818.

21. Marsh K, Forster D, Waruiru C, Mwangi I, Winstanley M, Marsh V, et al: Indicators of life-threatening malaria in African children. $N$ Engl I Med 1995, 332(21):1399-1404.

22. Dondorp A, Nosten F, Stepniewska K, Day N, White N: Artesunate versus quinine for treatment of severe falciparum malaria: a randomised trial. Lancet 2005, 366(9487):717-725.

23. Checkley AM, Smith A, Smith V, Blaze M, Bradley D, Chiodini PL, et al: Risk factors for mortality from imported falciparum malaria in the United Kingdom over 20 years: an observational study. BMJ 2012, 344(3):e2116.

24. Phillips A, Bassett P, Zeki S, Newman S, Pasvol G: Risk factors for severe disease in adults with falciparum malaria. Clin Infect Dis 2009, 48(7):871-878.

25. Berkley J, Mwarumba S, Bramham K, Lowe B, Marsh K: Bacteraemia complicating severe malaria in children. Trans R Soc Trop Med Hyg 1999, 93(3):283-286.

26. Berkley JA: Use of clinical syndromes to target antibiotic prescribing in seriously ill children in malaria endemic area: observational study. BMJ 2005, 330(7498):995.

27. Brentlinger $P E$, Behrens $C B$, Micek MA: Challenges in the concurrent management of malaria and HIV in pregnancy in sub-Saharan Africa. Lancet Infect Dis 2006, 6(2):100-111.

doi:10.1186/1471-2334-13-118

Cite this article as: Marks et al: Severe imported falciparum malaria among adults requiring intensive care: a retrospective study at the hospital for tropical diseases, London. BMC Infectious Diseases 2013 13:118.

\section{Submit your next manuscript to BioMed Central and take full advantage of:}

- Convenient online submission

- Thorough peer review

- No space constraints or color figure charges

- Immediate publication on acceptance

- Inclusion in PubMed, CAS, Scopus and Google Scholar

- Research which is freely available for redistribution 